Recibido: 25-noviembre-2013

Aceptado: 29-noviembre-2013

\title{
EL PAPEL DE LAS REVISTAS UNIVERSITARIAS
}

SILVIA EUGENIA CASTILLERO

Universidad de Guadalajara - México 


\section{RESUMEN}

En este ensayo, la autora hace hincapié en que el arte sobre todo es un lenguaje. Un sistema semántico que hace visible el sentido. Todo arte es un acto crítico. Nuestra humanidad biológica necesita una confirmación posterior, confirmación que la da la cultura. El arte, a diferencia de la publicidad y el periodismo, huye de las presiones inmediatas y encara el misterio de nuestro ser interior y nuestro ser social. Lamentablemente, en el día de hoy, los medios se han elevado la categoría de fines y han dado paso a la denominada "cultura light". Evidencia que el fomento del espíritu universitario auspicia el apogeo de la cultura, cuyo contenido axiológico radica en el perfeccionamiento espiritual y humano de la persona. La suprema operación del arte de hacer una revista literaria, consiste en dar forma a las diversas expresiones cuyo material es el lenguaje.

Palabras clave: arte, lenguaje, axiológico, cultura, cultura light, medios, fines.

\section{ABSTRACT}

In this essay, the author emphasizes that art is a kind of language. A semantic system that makes visible the meaning. All art is a critical act. Our biological humanity requires further confirmation, which gives culture. Art, unlike advertising and journalism, flee the immediate pressures and face the mystery of our inner selves and our social being. Unfortunately, today the media have high end category and have given rise to the so-called "culture light". The evidence that the promotion of school spirit sponsors the height of culture, the axiological content lies in the spiritual and human development of the person. The supreme operation of art in planning a literary magazine, is to shape the different expressions whose material is language.

Keywords: art, language, axiological, culture, culture light, media purposes. 
1.

George Steiner proclama el imperativo de aprender -una vez más- a ser humanos. "Debemos aprender de nuevo qué es lo que se halla comprendido dentro de una plena experiencia del sentido creado, dentro del enigma de la creación tal como es hecha sensible en el poema, la pintura, en la presentación musical". Porque efectivamente, pese a todo, en el fondo oscuro de esta nueva barbarie, permanecen los hacedores de arte.

El arte es ante todo lenguaje, un sistema semántico que vuelve sensible el sentido. Todo arte, música y literatura, dice Steiner, es un acto crítico, pues su hacer es una contra-declaración del mundo. Más que las personas ordinarias, el artista significativo se relaciona con el material crudo, anárquico, de la conciencia y la subconsciencia. Pues el lenguaje es ese aparato fabuloso que permite expresar un número indefinido de pensamientos o de cosas con un número finito de signos, que precisamente han sido escogidos de tal modo que son capaces de recomponer exactamente todo lo nuevo que se pueda querer decir y comunicar la evidencia de las primeras designaciones de las cosas.

El ser humano nace para la humanidad, es decir, nuestra humanidad biológica necesita una confirmación posterior; algo así como un segundo nacimiento en el que por medio de nuestro propio esfuerzo en el cultivo de nuestra razón y nuestro espíritu, y en la ineludible relación con otros humanos, se confirma definitivamente. Por ello la cultura, en su significación esencial, es algo que debe ser buscado y cultivado conscientemente en la vida de los humanos, en razón de que es el vehículo que nos conduce al ejercicio $y$ comprensión del humanismo.

Apuestas sobre lo perdurable, las creaciones estéticas son arcaicas, en el sentido que contienen en sí mismas, aún vivas, las fuentes distantes. Y más aún, el arte se desarrolla y se sustenta a través de la reflexión del arte precedente. Por eso, aunque a contracorriente, no es novedoso como el periodismo y la publicidad, más bien huye de las presiones inmediatas, para encarar el misterio del argumento sobre nuestro ser interior y nuestro ser social.

El proceso histórico nos dice que la cultura no es un acto de servidumbre a las condiciones materiales, sino una liberación de los elementos trascendentes de los humanos hacia la consecución de valores. Por ello es lamentable que ahora las ciencias parecen haber perdido el rumbo sin preocuparse por la razón de sí mismas. Cuando la definición de las ciencias se deshumaniza, sobresale en ellas el aspecto puramente funcional. Al perder su empaque cultural derivan hacia un pragmatismo que las disminuye por la necesidad práctica de la utilidad y la eficacia.

La desesperanza que hoy vivimos reside en que nuestras propias creaciones de civilización y de cultura se deslizan en un dinamismo ajeno, con un rumbo diverso, ocasionando que el hombre pierda sus dones de humanidad, sobre todo aquellos en que se funda su dignidad. Los medios se elevan a la categoría de fines para dar paso a una cultura "light". 
Un acucioso articulista, al analizar este declive del humanismo actual, refiere que después de la caída del muro de Berlín surgió esa forma hipersalvaje del capitalismo: el neoliberalismo, promovido por grupos de poder que han adoptado la libertad como el único criterio para que las sociedades crezcan, como si la libertad por sí misma y sin puntos de referencia humanos, pudiera en un futuro redimir a la humanidad.

Pero la libertad implica siempre el respeto y la solidaridad al semejante, primer estadio fundamental de la cultura. Ama -decía San Agustín- y haz lo que quieras. La perversión de la libertad, ausente del compromiso humano, se convierte en el derecho a la irresponsabilidad, al deterioro ilimitado.

"Nacemos humanos pero eso no basta -dice Savater- tenemos también que llegar a serlo porque ser humano es también un deber".

Hablar de humanismo no es manejar un concepto abstracto y ajeno, sino que implica un proyecto común en el más legítimo sentido de globalidad, porque ningún ser humano puede entenderse cabalmente a sí mismo si no comprende al resto de sus semejantes, en razón de que "la humanidad del otro siempre implica la mía".

Bien se ha ponderado con absoluta legitimidad que la Universidad y su esfuerzo constante por difundir la ciencia y la cultura, propende, no solo en su estructura curricular interna de enseñanzaaprendizaje, sino en su vasta labor de extensión, de acrecer y avalorar su designio vinculatorio de irradiación del espíritu universitario hacia la comunidad. Es evidente que el fomento del espíritu universitario auspicia el apogeo de la cultura, cuyo contenido axiológico radica en el perfeccionamiento espiritual y humano de la persona. No es difícil colegir de ello que una civilización bien vertebrada consta necesariamente de tales ingredientes: un ideal humano y una tradición literaria que lo expresa y lo mantiene vivo, al tiempo que posibilita su supervivencia por medio de la educación. En su afán de convicción comunicativa, toda Universidad debe de hacer vértice en una revista literaria o cultural.

Dirigir, guiar a alguien a través de la lectura equivale a tomar en nuestras manos los resortes de su ser.

No obstante, para forjar a ese tipo de hombre, no sólo se necesitan los artistas, sino interpretadores de esos lenguajes, porque en el arte una voz humana se dirige a otra. Se precisa pues de la mirada humana (no la snob, ni la académica, ni la erudita) que realice una lectura desde dentro y no desde el exterior y la periferia. Aprender de corazón, propone Steiner, pues "Io que conocemos de corazón se convierte en una acción efectiva dentro de nuestra conciencia, un 'marcapasos' en el crecimiento y la complejidad vital de nuestra identidad". ${ }^{1}$

2.

Las revistas culturales del México contemporáneo tienen como antecesores a Letras de México, El hijo pródigo, Contemporáneos, que en su época fueron

\footnotetext{
${ }^{1}$ George Steiner, "Presencias reales", en $L a$ Gaceta del FCE, México, p. 19. Traducción Salvador Mendiola.
} 
parte importante de la cultura de nuestro país. Y como antecedentes inmediatos están Diálogos y Plural, la primera dirigida por Ramón Xirau y la segunda por Octavio Paz. Desaparecida Plural, Paz se lanza a la empresa de fundar una de las revistas de literatura de mayor impacto en la cultura nacional: Vuelta, que junto con Nexos se convirtieron en espacios de interlocución entre escritores y lectores. Al fallecer Paz, surgen Letras libres y Paréntesis como herederas de Vuelta. De corte diferente, una de tendencia más antropológica y la otra literaria -respectivamente- logran convertirse otra vez en punto de reunión de la cultura mexicana, sin dejar de considerar la importancia y calidad de revistas como Biblioteca de México, La Gaceta, Crítica, Fractal, El poeta y su trabajo, entre otras.

Para la tradición de buena crítica propia de México, el número de revistas que existen actualmente, no cubre las necesidades de contar con un foro dentro del que ocurra un intercambio entre las personas dispuestas a compartir sus hallazgos de escritura y lectura con los lectores. Muchos han sido los intentos de sobrevivencia de publicaciones independientes que, sin embargo, han fracasado a causa de problemas económicos. Por ello creemos en la necesidad de lograr en esta nueva época de la revista Luvina la creación de un espacio habitable, que acoja al lector ávido y al crítico deseoso de mostrar sus hallazgos, que reúna el agitado afuera de este mundo globalizado y el íntimo temblor de las líneas de un poema.

La suprema operación del arte de hacer una revista literaria consiste en dar forma a las diversas expresiones cuyo material es el lenguaje. De ahí que el proceso al que nos entregamos los que realizamos Luvina sea un movimiento de indagación y tanteo en relación a la realidad: quehacer que es un conocimiento haciéndose en el mismo proceso del conocer. Cada número de la revista reúne trazos y voces, cada texto publicado modifica a todos los demás textos, pues cada uno de ellos está hecho del ingrediente vital de la experiencia. Internarse en las páginas de Luvina se vuelve vivencia pues constituye un mundo susceptible de ser abordado sólo en la emoción, las ideas, los ritmos que rezuman de cada uno de sus elementos y no fuera de ellos.

Decía Vila Matas que entender puede ser una condena, y no entender, la puerta que se abre. La condición de abierto de lo literario -lo abierto hacia el mundo y hacia el ser- significa para nosotros trabajar en la zona indesvelable, esa grieta desde donde lo humano se manifiesta a través de lo imaginario -entendido como la facultad de deformar las imágenes conocidas o como la búsqueda de imágenes ausentes- $y$ que constituye una zona de excepción, donde la vida es apresada y donde la literatura puede abandonarse a su propia naturaleza expresiva, a su propia respiración. Una revista es entonces un vínculo, vehículo que va de lo disperso y aparente del mundo circundante hacia el nudo de fondo de las cosas. Y completa su trayectoria en el ojo y en la conciencia del lector. Cruzar del extremo de lo descoyuntado por asilamiento -que es nuestra materia prima: que son cada uno de los autores agrupados en cada número de Luvina- hasta lo que posee sentido por estar articulado en un todo significante, es lograr un objeto único, perteneciente a una línea de tiempo privilegiada por constituir 
un ordenamiento eficaz de esa enigmática abundancia del mundo, como solía definir Borges a la literatura.

Diecisiete años de Luvina significa, entre otras cosas, haber atravesado la franja de lugares comunes del revistero nacional en la conquista de una visión particular y propositiva, una búsqueda constante de plumas de todo el orbe voces consagradas y voces nuevasentregadas a la tarea de arrancarle nuevas significaciones a la realidad, pues Luvina se interesa en mostrar a través de sus páginas la vida de las transacciones que ocurren entre lo real y lo irreal: allí donde la irrealidad inquieta a la realidad y donde ésta aprisiona a lo fantástico. 